\title{
Application of New Generation Information Technology in Disaster Prevention and Mitigation in Chemical Industry Park
}

\author{
Kaiyuan Wang ${ }^{1}$,Jianzhong Sun ${ }^{1, *}, \mathrm{Di} \mathrm{Li}^{1}$,Zhaohai Meng ${ }^{1}$,Chuanwu Sun ${ }^{1}$ \\ ${ }^{1}$ Safeite Engineering Technology Group Co. LTD \\ *Corresponding author. Email: sunjianzhong@sft360.com
}

\begin{abstract}
This paper firstly analyzes the present situation of disaster prevention and reduction and production safety in the chemical industry park, Then, on the basis of explaining the necessity and importance of disaster prevention and mitigation work in chemical parks, the significance of satellite remote sensing technology in the settlement and deformation monitoring of major dangerous installations and video image recognition technology for fire monitoring and early warning is discussed. Through the establishment of top-down safety management process, the early warning mode of disaster prevention and reduction risk can be realized horizontally to the edge and vertically to the bottom. Information technology can improve park supervision and disaster prevention and mitigation capabilities, as well as corporate response levels, help parks and companies effectively improve risk prevention capabilities, realize safety control thresholds, and improve hidden dangers and risk management capabilities. Finally, the application of information technology in disaster prevention and reduction in chemical industry park is illustrated with the example of disaster prevention and reduction information system. Practice shows that informationization construction plays an indispensable role in disaster prevention and mitigation in chemical industry park.
\end{abstract}

Keywords: disaster prevention and mitigation, Information Technology, Alert Management, chemical industry Park

\section{新一代信息技术在化工园区防灾减灾方面的应用}

\author{
王凯媛 ${ }^{1}$, 孙建中 ${ }^{1, *}$, 李迪 ${ }^{1}$, 孟兆海 ${ }^{1}$, 孙传武
}

\author{
${ }^{2}$ 赛飞特工程技术集团有限公司，青岛市崂山区名汇国际 1 号楼 7 层，266100 \\ “通讯作者, 电子邮箱： sunjianzhong@sft360.com
}

\section{摘要}

本文首先分析了化工园区防灾减灾和安全生产现状，而后在阐述化工园区防灾减灾工作必要性与重要性的基 础上，论述了卫星遥感技术在重大危险装置沉降变形监测和视频图像识别技术针对火情监测预警的意义，通 过建立从上而下安全管理流程，实现横向到边、纵向到底的防灾减灾风险预警模式，信息技术可提高园区监 管和防灾减灾能力以及企业应对水平，帮助园区与企业有效提高风险防范能力，实现安全管控关口前移，提 升隐患和风险管控治理能力。最后以化工园区防灾减灾信息化系统为例，阐述了信息化技术在防灾减灾中的 应用。实践表明，信息化建设在化工园区防灾减灾中的作用不可或缺。

关键词：防灾减灾，信息技术，预警管理，化工园区 


\section{1. 前言}

化工园区包括以石化化工为主导产业的新型 工业化产业示范基地、高新技术产业开发区、经 济技术开发区、专业化工园区及由各级政府依法 设置的化工生产企业集中区，是我国石化化工行 业发展的主要载体 ${ }^{[1]}$ 。随着新型城镇化的发展, 化 工企业将不断向园区聚集。不同园区之间发展水 平参差不齐、部分园区基础建设薄弱、管理不规 范、制度不健全、安全环保隐患等问题越来越突 出 $^{[2]}$ 。

由于化工企业大量使用易燃易爆、有毒有害 化学品, 具有生产使用场地集中的特点, 一旦发 生事故, 将对广大人民群众生命及财产安全造成 严重威胁 ${ }^{[3]}$ 。化工园区的现状已成为事故隐患和环 境污染的主要源头, 安全生产形势十分严峻。因 此, 加强化工园区安全生产监管就显得尤为重要。

2015 年, 工信部发布了《关于促进化工园区 规范发展指导意见》（工信部原 [2015]433 号） ${ }^{[1],}$ 从科学规划布局、加强项目管理、严格安全管理、 强化绿色发展、推进两化深度融合、完善配套服 务、加强组织管理七大方面提出了指导意见。

当前, 我国化工园区信息化建设处于起步阶 段，化工园区信息化是园区信息化中一个组成部 分, 根据我国产业在国民经济中所占的比例进行 合理推算, 目前化工园区信息化发展的投入规模 在 100 亿元左右 ${ }^{[4]}$, 为了进一步推动我国化工园区 信息化改造, 我国工信部印发了《关于促进化工 园区规范发展的指导意见》。

化工园区信息化发展即智慧化工园区的一种。 智慧园区由于其本身所具有的功能特性, 其建设 通常有侧重于服务其本身功能定位的特征 ${ }^{[5]}$, 如: 侧重于助推产业升级和服务能力的提升, 以服务 于园区产业经济的可持续发展。

另外, 化工园区信息化除了应具备其他信息 化园区所共有的政务管理、智能建筑、智慧交通、
园区服务等公共功能外，化工园区对环保、安全、 能源、安防等领域的应用需求也显得尤为迫切 ${ }^{[6]}$ 。 构建环保信息化、安全信息化、能源信息化、安 防信息化等功能于一体的智慧信息化平台将是信 息化化工区建设的重要内容, 而建立健全包括传 感器、视频等在内的全方位监测监控体系, 则是 实现对化工园区动态全面感知的重要方式和途径。

\section{2. 化工园区信息化建设现状}

目前化工园区信息化建设在以下几个方面还 存在不足。

\section{1、系统信息共享不足}

各业务系统相对独立、分散、集成度较低, 各业务系统之间功能无法融合, 无法实现双向数 据集成，缺少通用基础支撑软件打通底层，难以 解决 “信息孤岛” 问题。

\section{2、数据处理不够先进}

系统间数据库相互独立、类型不一, 缺乏标 准化统一接口, 缺少在安全机制下的跨部门信息 交换，与上级系统之间不能自动交换，响应的数 据规范与标准不够完善。影像资料、法律文书等 数据无法采集, 执法数据保全不完善, 信息利用 不方便，利用率低。

\section{3、业务应用效果不佳}

部分应用子系统操作复杂, 偏离实际使用需 求, 数据流程不直观, 统计分析功能零散。系统 综合预警能力弱, 部分系统只能进行单方面或单 元素数据预警，无法整合监测监控数据、生产运 行数据、安全管理数据进行综合预警。用户使用 体验差, 应用推进力度不够, 导致部分系统业务 功能效果差, 与现实工作要求脱节。

\section{4、实战服务效能不够}

化工园区部分现有系统偏重数据录入、信息 查询和统计报告功能, 注重从上到下的单向管理, 缺乏不同层级角色的定位与细分，面向基层的业 务功能不足, 基层人员无法获取企业运行现状; 
面向管理层的智能分析、风险预警以及决策支撑 等功能不强, 无法实现远程调度、远程指挥功能。

\section{3. 信息化解决方案}

通过物联网接入、大数据可视化分析、事件 联动、应急指挥调度、人工智能等新一代信息技 术, 以沃土数字平台为核心, 结合国内化工园区 建设管理经验, 打造安全、环保、绿色的智慧化 工园区, 将事件管理从事后处置变为事前防控, 保障生产安全, 提升安全水平 ${ }^{[7]}$ 。例如, 通过高分 影像数据, 可实时查看园区大气污染分布指数, 如图 1 所示。

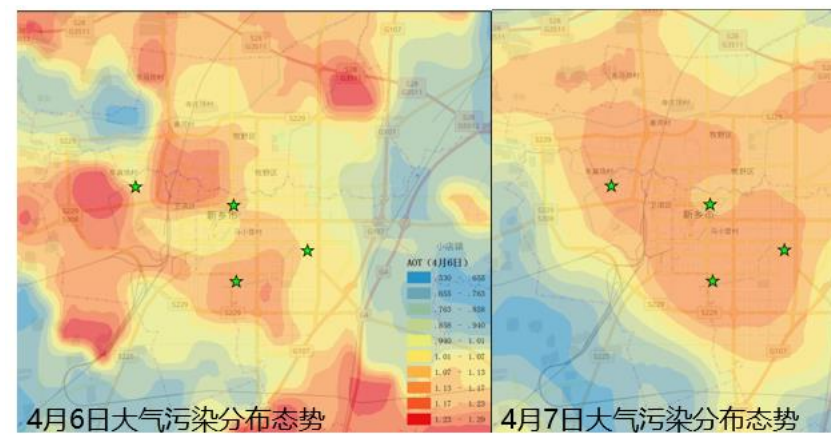

图 1 某化工园区 4 月 6 日-8 日大气污染分布指数 园区可视化管理系统一一为化工园区搭建全 景数字园区模型, 如图 2 所示, 采用多维一体化 GIS 展示模式, 对接园区现有信息系统, 实现园区 生产、检查、维保、安防等数据的全过程立体化 管控, 全面加强园区、储罐的运行监管和安全监 管; 同时系统可实现可视、高效的联防管控和预 警, 降低隐患、预防事故、推动生产、保障效益, 有效提高化工区的安全监管效率, 促进化工区安 全的可持续发展。

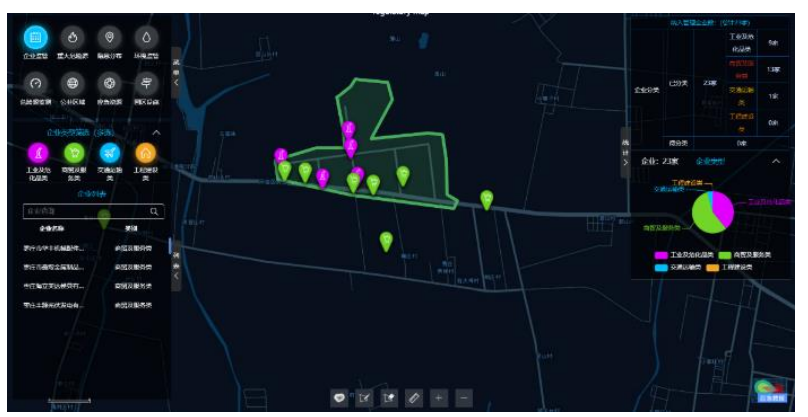

图 2 某化工园区全景数字园区模型
园区建设用地监管系统一一以高分卫星影像 分析技术为基础, 如图 3 所示, 利用多期高分辨率 影像数据对比提取新增建设用地信息, 对违规用 地、破坏地表植被及改变土地用途等行为进行实 时监测, 辅助国土管理部门定期采集和发现实际 新增建设用地。

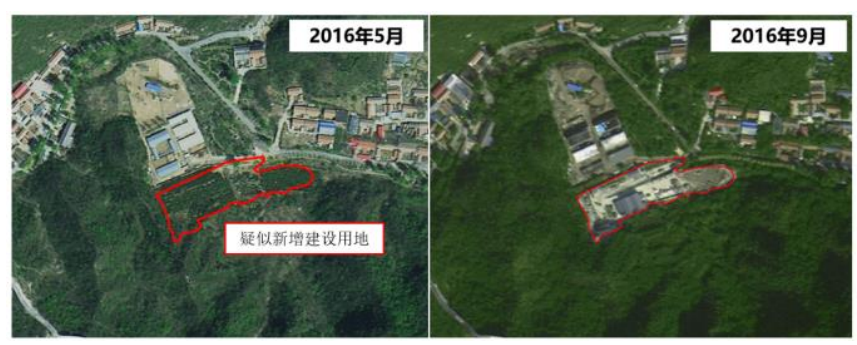

图 3 高分卫星建设用地分析影像

运用高分辨率雷达遥感技术, 可实现对化工 园区厂房建筑、重点罐区、自然山体等地表微小 形变自动监测预警, 无需人工监测, 不受天气影 响, 可实时调取重点区域沉降变化数据, 可快速 全面监测化工园区周边地表沉降变化情况, 评估 预警整体安全稳定性和潜在风险, 如图 4 所示。

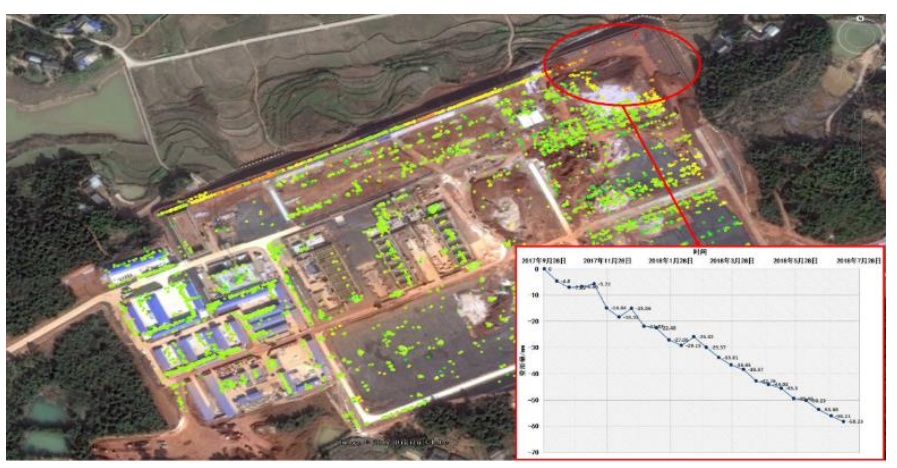

图 4 某化工园区地表沉降变化趋势分析 园区封闭式管理系统一一以 GIS 技术为基础, 结合人员、车辆高精度定位终端, 采用空间分析 方法对园区高危区域、重大危险源等区域非法入 侵进行自动判别, 实现对人员和车辆的可视化实 时位置监控和报警，使作业人员和车辆在园区内 作业全过程可追踪、可追溯, 实现动态监管。

园区安全应急指挥调度系统一一为化工园区 提供一套具备主动感知危险隐患的应急事故智能 化指挥调度管理软件。系统多场景应用模式 (日 常模式、应急模式和演练模式），为园区提供使 
用的日常业务监管和安全应急管理功能; 快速启 动应急预案并动态跟踪事故发展态势; 智能分析 模型实现对火灾、爆炸、危化品泄露等安全事故 动态模拟和演练。

对接天基气象卫星数据, 对雷电、台风、暴 雨、海啸、冰灾、雪灾等气象灾害进行可视化模 拟, 通过三维实景模拟分析技术实现对某化工园 区洪涝灾害波及范围的精准预测, 辅助防灾预案 和灾后重建方案决策, 为应急指挥和应急处置提 供技术支撑，如图 5 所示。

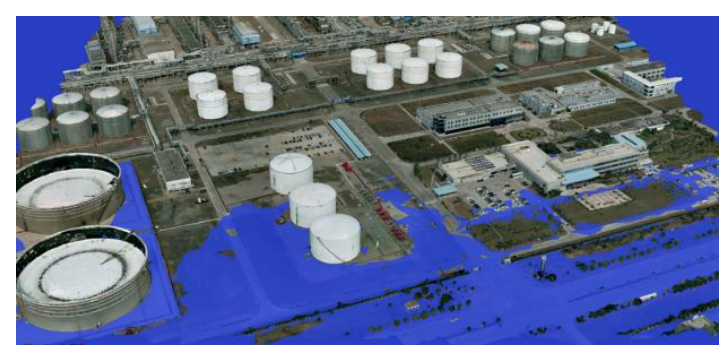

图 5 某化工园区洪涝灾害三维实景模拟技术

基于 VR 的化工区模拟演练及实战交互平台一 一基于化工区安全应急指挥调度系统, 结合 VR 智 能终端设计开发的以浸入式模拟演练、实战交互 为主的智能化培训教育演练系统，用于化工区日 常业务演练的外延和常规化演练培训。系统通过 化工区三维场景的真实还原, 让作业人员以浸入 式体验到亲临现场的感觉, 并可在场景中模拟作 业过程、学习作业方式。

园区安全信息管理（HSE）系统一一参照国家 安全标准体系, 为化工园区安全管理业务设计开 发的一套安全信息管理软件，提供基础信息管理、 安全检查管理、隐患信息管理、风险控制管理、 安全教育培训、各类操作规程和管理制度、事故 信息管理、消防安全管理、职业健康防范管理等 一系列安全管理功能，使化工区的安全监管向日 常业务管理渗透。将各业务系统数据与 BIM 建模技 术相结合，可直观反映园区各企业安全管理现状， 提升化工企业、人员安全意识, 保障化工园区安 全运行, 如图 6 所示。

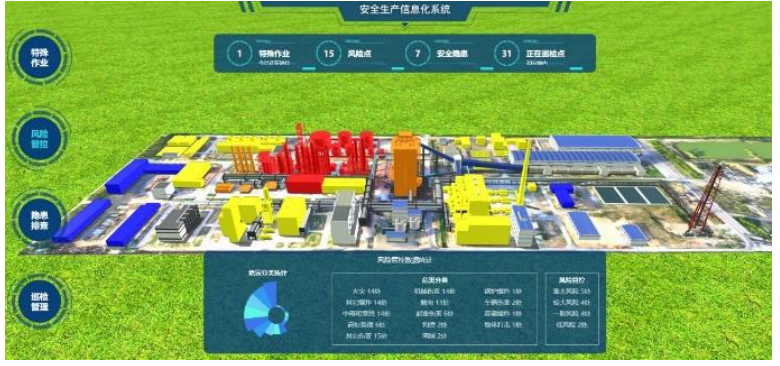

图 6 某化工园区安全信息管理（HSE）系统

利用新一代信息技术建成化工园区综合性信 息化应用平台, 实现一体化、协同化、平台化与 最优化。一是将信息化与工业化、城市化、生态 化融为一体，将虚拟化工园区与物理化工园区融 为一体; 二是实现化工园区各功能单元的业务协 同、规划、建设、管理、服务等活动流程的协同, 化工园区发展与城市化建设的协同; 三是实现产 业发展、政府管理与服务、居民生活的重要平台 应用, 注重化工园区发展的资源与环节的集成与 共享; 四是实现化工园区信息、技术、资本、人 力、土地等资源配置利用最优，资源价值得到最 大限度的释放, 形成化工园区竞争力。

\section{4. 结论与展望}

如何利用好信息化技术支撑园区的发展战略、 满足园区内企业智能化发展需求、进一步提升园 区的管理效率，是化工园区未来发展所面临的共 同课题。以新一代信息技术为手段，以智慧应用 为支撑，全面整合园区内外资源，实现园区基础 设施智能化、公共管理精细化、公共服务便捷化、 资源利用绿色化、产业发展智能化，促进园区发 展向产业集聚型、生态环保型转变。这对于拉动 产业经济, 促进行业发展, 推进两化深度融合及 转型升级都具有重要的作用。

未来信息技术在化工园区防灾减灾领域的应 用将围绕深化基础技术研究、加强资源整合、监 测感知与知识图谱应用研究等方面发展。未来园 区防灾减灾基础技术研究将重点关注单个灾害领 域、多灾种灾害链的机理和相关算法模型等的研 
究; 将目前园区各类生产运行数据、安全管理数 据、自然灾害监测感知数据等分散于不同部门的 数据进行有效整合和综合分析利用, 有利于推动 园区综合监测预警系统建设; 充分利用物联网感 知技术、知识图谱综合分析技术, 建设化工园区 防灾减灾感知网, 实现对重点灾害点位和区域实 现动态感知和提前预防。随着信息化技术在监测 预警、综合监管方面的深入应用, 化工园区防灾 减灾技术将趋于成熟和完善。

\section{参考文献}

[1]《关于促进化工园区规范发展指导意见》（工 信部原 [2015]433 号）。

[2]于萍, 高宏. 高度重视化工园区安全管理漏洞 [N]. 中国能源报, 2020-01-06 (004).

[3] 赵红刚. 信息化技术在化工企业安全监督管理 中的运用 [J]. 化工管理, 2020 (31) : 140-141.

[4]张悦. 基于风险分析的化工园区布局优化方法 研究 [D]. 中国矿业大学 (北京), 2013.

[5]杨凯瑞, 张毅, 何忍星. 智慧园区的概念、目标 与架构 $[J]$. 中国科技论坛, $2019(01): 115-122$.

[6]Liu Weiwei, Wang Wei. Current Situation of Chemical Industry Park in Shandong Province and Preliminary Discussion on Informatization Construction of Smart Park. SHANDONG CHEMICAL INDUSTRY, 2016, 45 (20) : 126-127.

[7]余华茂. 中国应急公共投入效率研究 [D]. 江西 财经大学, 2019. 